\title{
Desenvolvimento e avaliação de uma atividade baseada na solução de problemas em grupo para o ensino integrado de Fisiologia Humana
}

\section{Development and evaluation of a problem solving based group activity for the integrated teaching of human physiology}

\author{
Leandra Marques Chaves Melim ${ }^{1}$ \\ Carolina Nascimento Spiegel ${ }^{2}$ \\ Maurício Roberto Motta Pinto da Luz ${ }^{3}$
}

\section{RESUMO}

Atividades que integrem os sistemas fisiológicos utilizando situações-problema são promissoras para resolverem uma questão do ensino de fisiologia humana que é o estudo dos órgãos e sistemas de forma isolada. A aprendizagem baseada em problemas normalmente envolve a discussão entre grupos de estudantes que podem ser estruturados de diferentes formas, dentre elas podemos destacar as estratégias colaborativa e cooperativa. Na cooperação há uma divisão de tarefas entre os membros do grupo, enquanto que na colaboração não há uma divisão de tarefas a priori. No presente trabalho iremos descrever e avaliar uma atividade que integra diferentes sistemas fisiológicos, intitulada “Qual é o Diagnóstico?”. Esta foi aplicada na última aula da unidade de ensino de fisiologia humana, para 338 alunos de um Pré-vestibular Social localizado na região metropolitana do Rio de Janeiro. Estratégias cooperativa e colaborativa foram utilizadas, a fim de avaliar se a divisão de tarefas favorece a solução de um problema e verificar a percepção dos alunos acerca dessas duas estratégias. A proporção de soluções corretas para cada estratégia foi obtida a partir das respostas dadas por escrito ao final da atividade. Já a percepção dos alunos acerca das estratégias foi obtida por meio da análise do "Questionário de Avaliação”. Os resultados mostraram que nas duas estratégias a atividade foi bem aceita pelos alunos que a consideraram de dificuldade mediana. No entanto, a estratégia cooperativa favoreceu a solução do problema, apesar de problemas na dinâmica de grupo terem sido mais apontados do que na estratégia colaborativa.

Palavras-chave: aprendizagem colaborativa, aprendizagem cooperativa, ensino baseado na solução de problemas, fisiologia humana.

\footnotetext{
ABSTRACT

Activities that integrate physiological systems using problem situations are promising to solve a issue to teaching human physiology that is the study of organs and systems in isolation. Problem based learning usually involves discussion between groups of students that can be structured in different ways, among which we can highlight the collaborative and cooperative strategies. In cooperation there is a division of task among group members, while in collaborative there is no division of tasks defined a priori. In both cases the groups aim to achieve a common goal or solve a problem. In this paper we describe and evaluate

1 Fundação Oswaldo Cruz - Instituto Oswaldo Cruz - Laboratório de Avaliação em Ensino e Filosofia das Biociências.

2 Fundação Oswaldo Cruz - Instituto Oswaldo Cruz - Laboratório de Avaliação em Ensino e Filosofia das Biociências, Universidade Federal Fluminense - Departamento de Biologia Celular e Molecular.

3 Fundação Oswaldo Cruz - Instituto Oswaldo Cruz - Laboratório de Avaliação em Ensino e Filosofia das Biociências.
} 
a problem-based activity that integrates different physiological systems, entitled "What is the diagnosis?". The activity was implemented in the last class of the unit teaching human physiology to 338 students of a Social University Preparatory Course located in the metropolitan region of Rio de Janeiro. Cooperative and collaborative strategies was used to assess whether the division of tasks promotes problem solving and verify how students feel about these two strategies. The proportion of correct solutions for each strategy was obtained from answers written by students at the end of the activity. The students' perceptions about the strategies were obtained by analyzing the "Evaluation Questionnaire". The results showed that in the two strategies the activity was well accepted by the students who considered mid difficulty. However, the cooperative strategy favored the problem solution, despite problems in group dynamics were more pointed than in collaborative strategy.

Keywords: cooperative learning, collaborative learning, human physiology, problem based learning.

\section{INTRODUÇÃO}

A aprendizagem baseada em problemas (ABP) envolve a discussão entre grupos de estudantes para a solução de um problema complexo, com apoio e facilitação de um tutor ou professor (Aspy et al. 1993). Nesta abordagem os papéis de alunos e professores são modificados. O professor não é mais considerado o detentor do conhecimento e sim um facilitador da aprendizagem. Sua participação se dá por meio de questões abertas que têm por objetivo incentivar os alunos na busca da solução do problema e fazer com que eles exponham suas reflexões (Hmelo-Silver, 2004). A ABP teve início na metade dos anos 1960 em escolas médicas americanas (Duch et al. 2001), nas quais os problemas tomaram a forma de uma descrição de um paciente apresentando queixas e sintomas. A tarefa dos alunos, nesses casos é discutir, propor explicações para os sintomas e uma solução ou tratamento (Norman \& Schmidt, 2000).

A ABP normalmente envolve a discussão entre grupos de estudantes. O trabalho em grupo, por sua vez, é uma das metodologias mais acessíveis para ser utilizada em sala de aula, pois não demanda infraestrutura especial, mas muda o foco do ensino centralizado no professor para um ensino centralizado no aluno (Gaudet et al. 2010). De acordo com Jonhson e Jonhson (2009), Sharan (2010) e Slavin (2010) os estudantes podem aprender mais quando trabalham em grupo do que individualmente. Ao trabalhar em grupo, os estudantes têm oportunidade de discutir, argumentar e refletir sobre a tarefa, o que favorece a aprendizagem (Kirschner et al. 2009). No entanto, Blumenfeld et al. (1996) e Torres e Irala (2007) apontam que os efeitos do trabalho em grupo dependem de como o grupo é organizado, das tarefas a realizar e do perfil dos participantes.

As estratégias educativas que envolvem trabalhos em grupos podem variar em muitos aspectos, como por exemplo, o tamanho e a composição dos grupos, bem como os tipos de interações entre os membros do grupo e entre os grupos (Johnson et al. 2000). Dentre essas estratégias bem sucedidas, destacam-se as estratégias colaborativa e cooperativa, que promovem interações positivas entre os alunos. Em ambos os casos os estudantes trabalham juntos para alcançar um objetivo comum, porém organizados de modos diferentes (Dillenbourg, 1999). Embora alguns autores considerem os termos colaboração e cooperação como sinônimos (Johnson et al. 2000), no presente trabalho iremos assumir que a colaboração e a cooperação são estratégias diferentes, principalmente em função da organização interna dos membros dos grupos como proposto por diversos estudos (Panitz, 1997; Dillenbourg, 1999; McInnerney e Roberts, 2004; Torres \& Irala, 2004).

A aprendizagem cooperativa é caracterizada pela divisão de tarefas na qual cada membro do grupo é responsável por parte da informação necessária para resolver um problema, o que aumenta a responsabilidade dos indivíduos dentro do grupo (Panitz, 1997). O resultado final só poderá ser atingido se todos os envolvidos desempenharem suas funções e coordenarem seus esforços para ensinarem uns aos outros (Slavin, 1983). A aprendizagem 
colaborativa, por sua vez, é caracterizada por processos relativamente não estruturados, nos quais os membros do grupo trabalham em conjunto, sem divisão de tarefas a priori a fim de alcançarem um objetivo (Dillenbourg, 1999).

Apesar de suas diferenças, tanto as abordagens colaborativas quanto as cooperativas visam promover a aprendizagem ativa quando comparadas a aulas expositivas, pois o trabalho em grupo estimula a interação entre os alunos, o desenvolvimento de habilidades de negociação, auto-regulação da aprendizagem e resolução de problemas (Torres \& Irala, 2007).

De acordo com os Parâmetros Curriculares Nacionais (2000: p.18), o estudo das funções vitais, deve ser feito de forma integrada com destaque para fisiologia humana: "Ao abordar as funções acima citadas (funções vitais), é importante dar destaque ao corpo humano, focalizando as relações que se estabelecem entre os diferentes aparelhos e sistemas e entre o corpo e o ambiente, conferindo integridade ao corpo humano, preservando o equilíbrio dinâmico que caracteriza o estado de saúde.”

Rodríguez-Barbero e López-Novoa (2008), porém, destacam que o principal problema no estudo da Fisiologia Humana é que os órgãos e sistemas são estudados separadamente e muitas vezes explicados por diferentes professores. Para Pelaez, (2002) os estudantes veem a Fisiologia como uma coleção isolada de vocabulário e fatos a serem memorizados. Um dos poucos estudos empíricos existentes parece corroborar essa percepção. De fato, Vanzela et al. (2007) mostraram que a maioria dos alunos não relaciona os sistemas para explicar situações-problema relacionadas à saúde e ao cotidiano. Os autores sugeriram que a realização de atividades que integrem os sistemas fisiológicos utilizando situações-problema seria uma das maneiras de promover a compreensão integrada dos sistemas.

Alguns autores realizaram trabalhos promissores combinando a aprendizagem cooperativa e a solução de problemas. Em um trabalho realizado com estudantes da graduação que cursaram a disciplina Física, os autores constataram que as soluções dos problemas dos grupos foram significativamente melhores do que as soluções produzidas individualmente pelos melhores alunos de cada grupo em um problema similar (Heller \& Hollabaugh, 1992). Dees (1991) comparou o desempenho de grupos cooperativos e colaborativos de estudantes de graduação na solução de problema de matemática, demonstrando que os grupos cooperativos tiveram um desempenho maior. Tarim (2009) realizou um estudo com 54 crianças com idades de 5 a 6 anos de escolas privadas da Turquia e constatou que os grupos cooperativos tiveram um desempenho significativamente maior na solução de problemas de matemática do que os alunos que resolveram problemas de maneira individual ou em grupos colaborativos. Estes estudos indicam, portanto, que a aprendizagem cooperativa favorece a solução de problemas quando comparada a estratégias colaborativas ou individuais.

No presente trabalho iremos descrever e avaliar uma Atividade investigativa baseada na solução de problemas, intitulada “Qual éo Diagnóstico?”, que integra diferentes sistemas fisiológicos. A Atividade foi aplicada utilizando a estratégia cooperativa Jigsaw (Aronson \& Patnoe, 1997) e uma estratégia colaborativa a fim de avaliar qual das abordagens favorece a solução de um problema que integra diversas funções fisiológicas, além de caracterizar a percepção dos alunos acerca dessas duas estratégias.

\section{METODOLOGIA}

\section{1 Contexto do estudo}

Os alunos que participaram desta pesquisa fazem parte de um Pré-vestibular Social. Este Pré-Vestibular Social (PVS) é dirigido a interessados que já concluíram ou que estão matriculados no último ano do Ensino Médio e que desejam concorrer a vagas nos concursos vestibulares para acesso ao ensino superior, mas que não têm condições de arcar com os custos dos cursos particulares. O PVS é totalmente gratuito, inclusive o material didático e está presente em cerca de 38 municípios do estado do Rio de Janeiro (Bastos et al. 2010). 


\section{2 Participantes}

A Atividade “Qual é o Diagnóstico?” foi realizada com 338 alunos de três polos do Pré-Vestibular Social localizado na região metropolitana do Rio de Janeiro. As turmas que participaram do estudo eram compostas por alunos que estavam cursando o último ano do Ensino Médio e por alunos que já haviam concluído esse nível de ensino. A Tabela 1 mostra o número de alunos, grupos e turmas divididos por estratégia.

Tabela 1 - Número de alunos e grupos, divididos por estratégia, que realizaram a Atividade “Qual é o diagnóstico?”

\begin{tabular}{|c|c|c|c|c|c|}
\hline & \multirow{2}{*}{ Alunos } & \multicolumn{3}{|c|}{ Grupos } & \multirow{2}{*}{ Turmas } \\
\hline & & Cursistas* & Formados** & Total & \\
\hline Cooperativa & 162 & 20 & 31 & 51 & 10 \\
\hline Colaborativa & 176 & 21 & 34 & 55 & 9 \\
\hline Total & 338 & 41 & 65 & 106 & 19 \\
\hline
\end{tabular}

\section{3 Descrição da Atividade “Qual é o Diagnóstico?”}

A Atividade "Qual é o diagnóstico" integra conhecimentos de três sistemas: Circulatório, Excretório e Respiratório visando a solução de um problema relacionado à saúde. A Atividade teve como objetivo permitir que os alunos determinassem qual o problema de saúde que estaria causando os sintomas de uma paciente hipotética. Para tanto, os alunos deveriam estudar os sintomas da paciente, analisar as possíveis causas para cada um deles e verificar quais doenças podem ser descartadas com base em exames disponíveis. Com isso, pretendemos fornecer aos alunos uma visão mais integrada dos sistemas, além de exercitar a capacidade de interpretação de gráficos, tabelas, de trabalho em equipe e de resolução de problemas.

A Atividade "Qual é o Diagnóstico?” é composta por quatro fichas denominadas: "Ficha Médica”, e três "Fichas de Consulta" (Apêndice 1). A "Ficha "Médica" apresenta o peso, a idade da paciente e seus principais sintomas: "fraqueza e palidez", "hipertensão arterial" e "inchaço dos tornozelos". Cada "Ficha de Consulta" detalha um dos sintomas da paciente e apresenta três possíveis fatores ou doenças que podem causá-lo. Além disso, cada "Ficha de Consulta" mostra o resultado de um exame médico diferente.

Alguns fatores ou doenças só podem ser descartados por meio da análise dos resultados dos exames. Outros fatores ou doenças podem ser descartados analisando a "Ficha Médica". O Quadro 1 mostra o tema e as informações contidas em cada ficha, o exame, as possíveis causas dos sintomas e as conclusões que os alunos podem chegar ao analisarem cada uma delas. Nenhuma ficha sozinha fornece o diagnóstico correto da paciente. Para solucionar o problema os alunos devem interpretar a "Ficha Médica" e o conteúdo de todas as "Fichas de Consulta".

É importante destacar que o exame presente em cada "Ficha de Consulta" não está relacionado ao sintoma descrito na mesma. Por exemplo, a "Ficha de Consulta- Palidez" traz o resultado do exame de glicose que ajudará os alunos a descartar a diabetes que aparece como um dos possíveis fatores para o aumento da pressão arterial na "Ficha de Consulta-Pressão" (Quadro 1; Apêndice I). Isso foi feito de maneira proposital, para garantir a divisão de tarefas nos grupos cooperativos. É necessário realizar um cruzamento das informações para dar o diagnóstico correto de insuficiência renal, a única doença capaz de provocar os três sintomas ao mesmo tempo conforme demonstrado no Diagrama 1. 


\section{4 Aplicação da Atividade}

A Atividade “Qual é o Diagnóstico?” foi utilizada na última aula da unidade de ensino relativa à Fisiologia Humana. Esta unidade foi composta de oito aulas, em ordem cronológica: sistemas digestório, circulatório, respiratório e por último o sistema excretório. Para cada sistema houve uma aula para exposição dialogada do tema (55 minutos) e uma aula de exercícios (55 minutos). A Atividade “Qual é o Diagnóstico?” foi realizada uma semana após a correção dos exercícios sobre sistema excretório. Em nenhuma etapa da realização dessa atividade os alunos contaram com ajuda do professor para resolução do problema, que apenas incentivou e tirou dúvidas sobre a dinâmica de execução da tarefa.

\section{Quadro 1 - Descrição do tema, conteúdo e exames presentes em cada ficha do material da Atividade “Qual é o diagnóstico?”, assim como as possíveis causas dos sintomas e as conclusões que podem ser alcançadas pelos alunos.}

\begin{tabular}{|c|c|c|c|c|c|}
\hline Ficha & Tema & Informações & Possíveis Causas & Exame & Conclusão \\
\hline Médica & $\begin{array}{l}\text { Informações } \\
\text { gerais }\end{array}$ & $\begin{array}{l}\text { - peso e idade } \\
\text { - fraqueza e palidez } \\
\text { - inchaço ao redor } \\
\text { dos olhos e nos } \\
\text { tornozelos } \\
\text { - pressão máxima de } \\
\text { 17mmHg e mínima } \\
\text { de } 10 \mathrm{mmHg}\end{array}$ & $\begin{array}{l}\text { As possíveis } \\
\text { causas para os } \\
\text { sintomas listados } \\
\text { são levantadas } \\
\text { pelos próprios } \\
\text { alunos }\end{array}$ & Nenhum & $\begin{array}{l}\text { A paciente é idosa, não } \\
\text { obesa e não faz uso de } \\
\text { bebidas alcoólicas e nem } \\
\text { de cigarros. Não apresenta } \\
\text { febre nem episódios de } \\
\text { sangramento ou dores } \\
\text { abdominais. }\end{array}$ \\
\hline $\begin{array}{l}\text { Consulta } \\
\text { Palidez }\end{array}$ & Anemia & $\begin{array}{l}\text { - Tabela com o } \\
\text { resultado do } \\
\text { hemograma } \\
\text { (série vermelha) } \\
\text { da paciente e os } \\
\text { respectivos valores } \\
\text { de referência*. } \\
\text { *Fonte: Failace, } \\
2009 \\
\text { - Texto explicando o } \\
\text { que é anemia e suas } \\
\text { possíveis causas }\end{array}$ & $\begin{array}{l}\text { - Perda de } \\
\text { hemácias } \\
\text { por meio de } \\
\text { sangramentos } \\
\text { - Insuficiência } \\
\text { Renal } \\
\text {-Deficiência de } \\
\text { Ferro }\end{array}$ & $\begin{array}{l}\text { Taxa de glicose } \\
\text { sanguínea em duas } \\
\text { datas distintas } \\
\text { e os valores de } \\
\text { referência* } \\
\text { Resultado mostrado } \\
\text { em um gráfico de } \\
\text { barras } \\
\text { *Fonte: Brasil. } \\
\text { Ministério da } \\
\text { Saúde, } 2006\end{array}$ & $\begin{array}{l}\text { A paciente está com } \\
\text { anemia, que pode ser } \\
\text { provocada por insuficiência } \\
\text { renal ou deficiência de } \\
\text { ferro, uma vez que a ficha } \\
\text { médica informa que ela não } \\
\text { apresenta nenhum tipo de } \\
\text { sangramento. } \\
\text { O exame mostra que os } \\
\text { níveis de glicose estão } \\
\text { normais }\end{array}$ \\
\hline $\begin{array}{l}\text { Consulta } \\
\text { Pressão }\end{array}$ & $\begin{array}{l}\text { Hipertensão } \\
\text { Arterial }\end{array}$ & $\begin{array}{l}\text { - Tabela com a } \\
\text { classificação da } \\
\text { pressão arterial em } \\
\text { indivíduos maiores } \\
\text { de } 18 \text { anos* } \\
\text { - Texto explicando } \\
\text { o que é a pressão } \\
\text { arterial e as } \\
\text { possíveis causas do } \\
\text { seu aumento. } \\
\text { *Fonte: Brasil. } \\
\text { Minstério da } \\
\text { Saúde, } 2006 .\end{array}$ & $\begin{array}{l}\text { - Insuficiência } \\
\text { Renal } \\
\text { - Obesidade } \\
\text { - Diabetes tipo II }\end{array}$ & $\begin{array}{l}\text { Eletrocardiograma } \\
\text { da paciente e de } \\
\text { um indivíduo } \\
\text { sem problemas } \\
\text { cardíacos* } \\
\text { *Fonte: Brasil. } \\
\text { Ministério da } \\
\text { Saúde, } 2003 .\end{array}$ & $\begin{array}{l}\text { A paciente está com } \\
\text { hipertensão moderada, } \\
\text { que pode ser provocada } \\
\text { pela insuficiência renal ou } \\
\text { diabetes, uma vez que a } \\
\text { ficha médica informa que } \\
\text { a paciente está dentro da } \\
\text { faixa de peso. } \\
\text { O exame mostra que o } \\
\text { eletrocardiograma está } \\
\text { normal }\end{array}$ \\
\hline $\begin{array}{l}\text { Consulta } \\
\text { Inchaço }\end{array}$ & Edema & $\begin{array}{l}\text {-Texto explicando } \\
\text { o que é um edema } \\
\text { e suas possíveis } \\
\text { causas }\end{array}$ & $\begin{array}{l}\text { - Aumento da } \\
\text { pressão dentro } \\
\text { das veias } \\
\text { e capilares } \\
\text { (varizes) } \\
\text { - Insuficiência } \\
\text { cardíaca } \\
\text { - Insuficiência } \\
\text { Renal }\end{array}$ & $\begin{array}{l}\text { Tabela com } \\
\text { dosagem de ferro } \\
\text { e ferritina e os } \\
\text { respectivos valores } \\
\text { de referência* } \\
\text { *Fonte: Paiva, } \\
\text { Rondo e Guerra- } \\
\text { Shinohara, } 2000\end{array}$ & $\begin{array}{l}\text { O inchaço dos tornozelos } \\
\text { pode ser provocado pela } \\
\text { insuficiência cardíaca ou } \\
\text { renal, já que varizes não } \\
\text { provocariam os demais } \\
\text { sintomas da paciente. } \\
\text { O exame mostra que as } \\
\text { dosagens de ferro e ferritina } \\
\text { estão normais }\end{array}$ \\
\hline
\end{tabular}




\section{Diagrama 1 - Diagrama mostrando como é possível chegar ao diagnóstico a partir do cruzamento das informações presentes nas Fichas da Atividade “Qual é o diagnóstico?”}

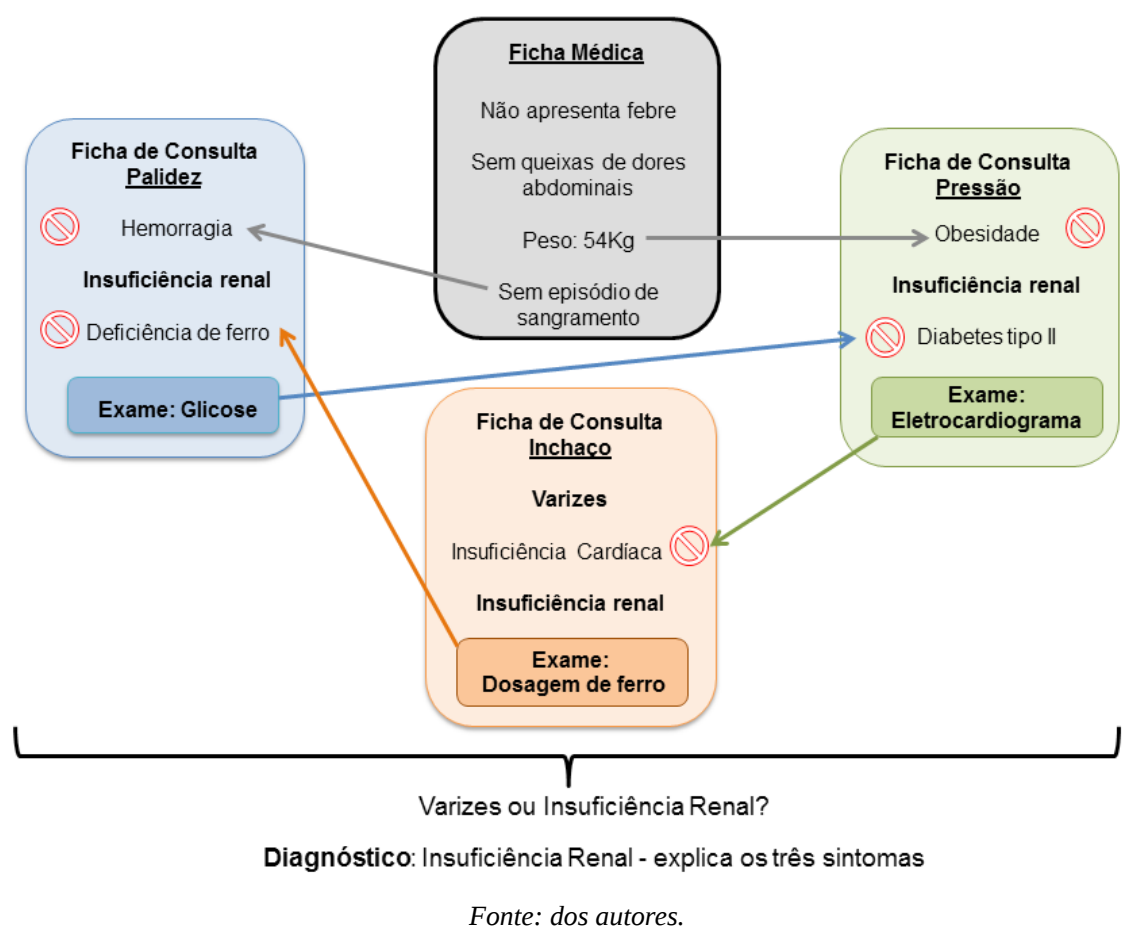

\section{5 Descrição das estratégias utilizadas em sala de aula}

Foi explicado aos alunos que seria realizada uma atividade na qual eles se comportariam como uma junta médica para dar o diagnóstico para uma paciente hipotética. Para isso, eles deveriam formar grupos e analisar o material fornecido. A Atividade "Qual o diagnóstico?" foi aplicada utilizando-se uma estratégia cooperativa e outra colaborativa, como descrito a seguir.

\section{6 Estratégia Cooperativa}

A estratégia cooperativa foi realizada utilizando a metodologia cooperativa Jigsaw (Aronson \& Patnoe, 1997). Nesta estratégia, o professor divide os alunos em pequenos grupos e cada membro do grupo recebe um texto com parte do assunto que será tratado. Os alunos devem explicar uns aos outros o que entenderam de seus textos. O objetivo é entender primeiro as partes, para posteriormente alcançar compreensão do todo e garantir a participação de todos (Aronson \& Patnoe, 1997). No presente trabalho, os grupos cooperativos foram organizados de acordo com as seguintes etapas:

Etapa 1: A turma foi dividida em grupos de 3 a 4 alunos, denominados de "grupo de origem”. Cada grupo recebeu apenas a "Ficha Médica" da paciente e teve 10 minutos para analisá-la e discutir as possíveis causas dos sintomas por ela apresentados.

Etapa 2: Cada membro do grupo recebeu uma "Ficha de Consulta" diferente: Palidez, Pressão ou Inchaço. Em seguida, os grupos de origem foram desfeitos e os membros de diferentes grupos que possuíam as mesmas "Fichas de Consulta" formaram um novo grupo, composto por três alunos, denominado de grupo de experts. Cada um dos grupos de experts teve 20 minutos para analisar e discutir o conteúdo de sua "Ficha de Consulta". Considera-se, para efeitos práticos, que cada aluno deste tipo de grupo se torna um "expert" no assunto de sua "Ficha de Consulta". 
Etapa 3: Os experts em cada "Ficha de Sintomas" retornaram ao Grupo de Origem e compartilharam com os demais membros, o conteúdo discutido no Grupo de experts, garantindo assim a divisão de tarefas (conhecimentos) e o compartilhamento das informações entre os membros do Grupo de Origem. O diagnóstico da paciente foi dado pelo Grupo de Origem por escrito na própria "Ficha Médica" da paciente. Esta etapa teve 20 minutos de duração. O conjunto da Atividade totalizou 50 minutos (uma duração compatível com as aulas escolares). A Figura 1 ilustra a dinâmica adotada nesta estratégia.

\section{7 Estratégia Colaborativa}

Nesta estratégia os alunos também foram divididos em grupos de 3 a 4 alunos, no entanto, não foi estabelecida uma divisão de tarefas a priori. O grupo, assim como na estratégia cooperativa, teve 10 minutos para analisar apenas a "Ficha Médica" da paciente. Em seguida o grupo recebeu as três "Fichas de Consulta" e teve 40 minutos para analisá-las em conjunto e propor por escrito o diagnóstico para a paciente. Nesta estratégia os próprios membros do grupo se organizaram a fim de discutir e propor o diagnóstico. O conjunto da atividade também teve a duração de 50 minutos.

Figura 1 - Metodologia cooperativa Jigsaw utilizada para a realização da atividade “Qual é o diagnóstico?”.

Formação dos grupos e distribuição da Ficha Médica

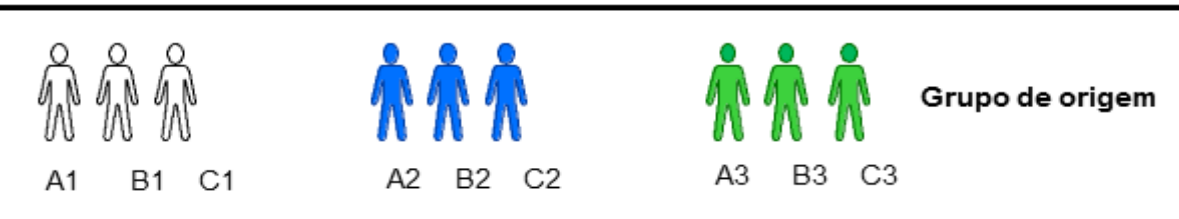

Formação do grupo de experts e distribuição das Fichas de Consulta
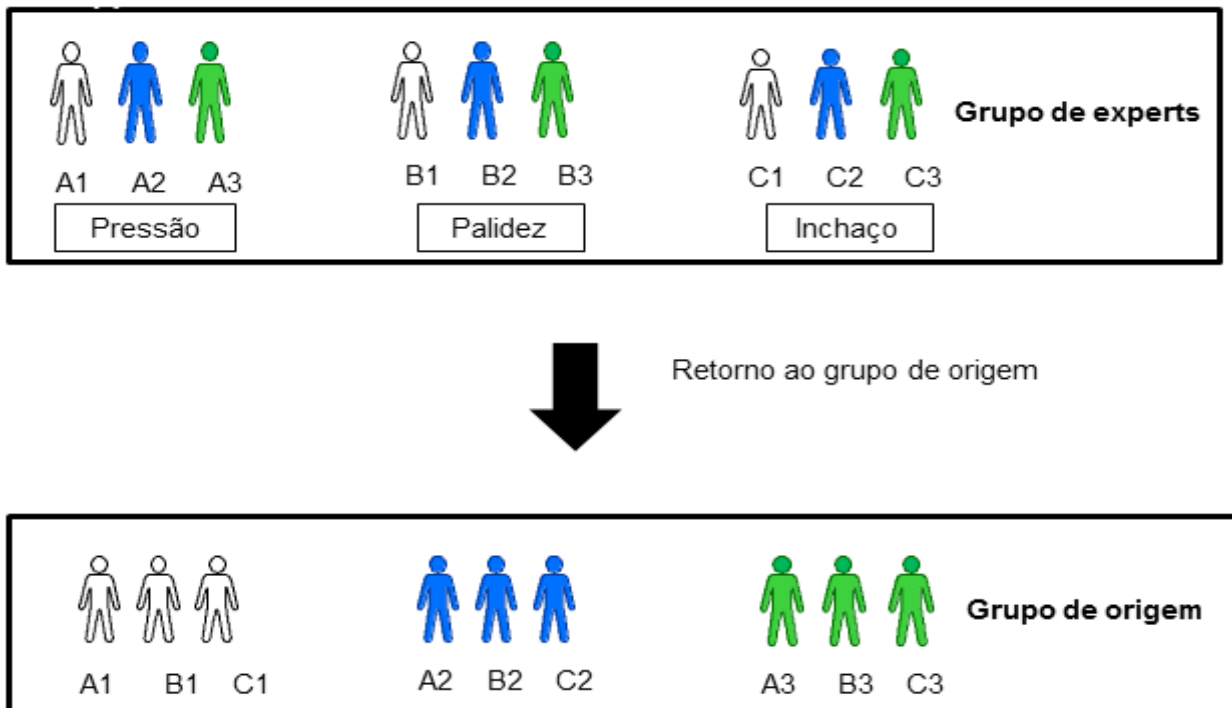

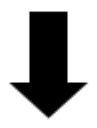

Diagnóstico

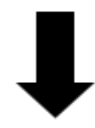

Diagnóstico

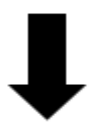

Diagnóstico

Fonte: dos autores. 


\section{8 Avaliação das estratégias}

As soluções apresentadas por escrito pelos grupos foram classificadas em corretas e incorretas. As soluções em branco foram agrupadas junto com as soluções incorretas. Para ser considerada correta uma resposta deveria conter o diagnóstico de insuficiência renal, acompanhado de uma justificativa coerente baseada no conteúdo das "Fichas de Consulta". Eram consideradas justificativas corretas as respostas que destacavam que: (i) a fraqueza e a palidez foram causadas pela incapacidade dos rins em produzir o hormônio (eritropoetina) responsável pela produção de hemácias; ou que (ii) a hipertensão arterial está relacionada à perda progressiva da capacidade dos rins em excretar sódio, resultando em uma sobrecarga de volume de sangue nos vasos ou que (iii) o inchaço é provocado pelo aumento na quantidade de água corporal em consequência do excesso de sal. Além disso, as respostas corretas foram analisadas de acordo com a quantidade de sintomas relacionados à insuficiência renal descritos. Foram consideradas corretas também as respostas que apresentavam o diagnóstico de insuficiência renal por meio de uma análise dos exames que resultasse na exclusão das demais doenças possíveis. As soluções foram analisadas independentemente por dois avaliadores, sendo o grau de concordância entre eles de $87 \%$. As respostas nas quais houve discordância foram discutidas até que se chegasse a um consenso.

Em apenas 7 turmas foi possível, por razões de organização do Curso, realizar uma avaliação adicional da Atividade. Na aula seguinte à Atividade, foi realizada a discussão da solução correta e os alunos puderam sanar suas dúvidas com o professor. Após a discussão da solução correta da Atividade, 41 alunos dos grupos cooperativos e 42 alunos dos grupos colaborativos responderam individualmente a um “Questionário de Avaliação” acerca da dificuldade da solução do problema, a aceitação do trabalho em grupo e da dinâmica do grupo (Anexo I).

Para efeitos de análises estatísticas, realizamos uma conversão das respostas para valores numéricos, de forma que à alternativa "muito fácil” foi atribuída o valor mínimo 1, seguido do valor 2 para a alternativa "fácil” e assim sucessivamente, sendo 5 o valor máximo equivalente a "muito difícil”. Quanto à dinâmica do grupo, foi apresentada aos alunos uma lista, adaptada do trabalho de Ebrahim (2012), com potenciais problemas que podem ou não acontecer em trabalhos realizados em grupos. Cada aluno poderia assinalar caso tivesse percebido algum desses problemas durante a Atividade.

As proporções de soluções corretas para a Atividade e a quantidade de respostas que apontavam problemas na dinâmica do grupo foram analisadas utilizando-se o Teste de Fisher. Já a quantidade de sintomas relacionados à Insuficiência renal, a aceitação da Atividade e a percepção da dificuldade na solução foram analisadas utilizando-se o teste t. as diferenças foram consideradas significativas, apenas quando $p<0,05$. O presente trabalho tem a aprovação do Comitê de Ética e Pesquisa Envolvendo Seres Humanos sob o número CAAE: 12957413.8.0000.5248.

\section{RESULTADOS E DISCUSSÃO}

A Atividade “Qual é o Diagnóstico?” baseada na solução de problemas para a integração de temas de Fisiologia Humana teve como objetivo não apenas a discussão de Fisiologia Humana de forma integrada, como também possibilitar o aprimoramento de habilidades como raciocino, síntese de informações, interpretação de gráficos e tabelas e trabalho em grupo.

A proporção de soluções corretas para a Atividade “Qual éo Diagnóstico?” foi feita a partir das respostas dadas pelos grupos na "Ficha Médica". O Quadro 2 mostra exemplos de respostas corretas e incorretas para a Atividade, assim como das quantidades de justificativas usadas na solução. 
Quadro 2 - Exemplos de respostas corretas e incorretas para a atividade “Qual é o
diagnóstico?” e exemplos da quantidade de justificativas (destacadas em negrito)
utilizadas nas respostas dos alunos para explicar o quadro de Insuficiência Renal.

\begin{tabular}{|c|c|c|c|}
\hline Categorias & & Exemplos de Respostas & $\begin{array}{l}\text { Quantidade de } \\
\text { justificativas }\end{array}$ \\
\hline \multirow{4}{*}{ Correta } & \multirow{3}{*}{ 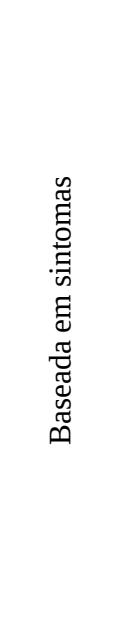 } & $\begin{array}{l}\text { "A paciente apresenta quadro clínico de insuficiência renal. O inchaço dos } \\
\text { tornozelos e o aumento da pressão arterial são ocasionados pela perda da } \\
\text { capacidade dos rins em excretar sódio. Esta deficiência renal ocasiona também } \\
\text { a diminuição da capacidade do rim em produzir o hormônio eritropoetina, o } \\
\text { que ocasionará a queda do hematócrito e anemia, culminando em um quadro de } \\
\text { fraqueza.” }\end{array}$ & 3 \\
\hline & & $\begin{array}{l}\text { “A paciente está com Insuficiência Renal, pois essa doença causa a perda } \\
\text { da capacidade dos rins em excretar sódio, assim ocorre acúmulo de sal no } \\
\text { organismo, o que leva ao aumento da pressão arterial. Além disso, o rim diminui } \\
\text { a capacidade de produzir o hormônio eritropoetina que controla a produção de } \\
\text { hemácias.” }\end{array}$ & 2 \\
\hline & & $\begin{array}{l}\text { “A paciente apresenta quadro de Insuficiência Renal, devido a diminuição na } \\
\text { produção do hormônio que estimula a produção de glóbulos vermelhos na } \\
\text { medula óssea. Isso leva a paciente a apresentar queda no seu hematócrito e } \\
\text { consequente fraqueza e palidez” }\end{array}$ & 1 \\
\hline & 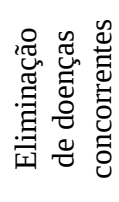 & $\begin{array}{l}\text { “Analisando a ficha médica, a obesidade foi descartada. O resultado do } \\
\text { eletrocardiograma é normal, assim como os níveis de glicose o que exclui a } \\
\text { diabetes. O ferro também está normal. Conclusão: a paciente está hipertensa, com } \\
\text { inchaço nos tornozelos e ao redor dos olhos devido ao quadro de Insuficiência } \\
\text { Renal” }\end{array}$ & Não se aplica* \\
\hline Incorreta & & $\begin{array}{l}\text { "O grupo chegou a conclusão que a paciente apresenta sintomas referentes a } \\
\text { insuficiência renal por conta da fraqueza e palidez causando anemia e devido ao } \\
\text { aparecimento de inchaço dos tornozelos e ao redor dos olhos.” }\end{array}$ & Não se aplica \\
\hline
\end{tabular}

* Uma vez que estas respostas foram dadas com base nos exames e consequente exclusão das demais doenças, não foi possível quantificar os sintomas relacionados à insuficiência renal na solução do problema.

Fonte: dos autores.

Os resultados relativos à solução do problema mostram que grupos cooperativos tiveram uma porcentagem de acertos significativamente maior $(70,6 \%)$ do que os grupos que trabalharam colaborativamente $(43,6 \%)$ (Figura 2). No entanto, não foram encontradas diferenças significativas nas quantidades médias de justificativas usadas para solucionar o problema das estratégias cooperativa $(2,36 \pm 0,76)$ e colaborativa $(2,44 \pm 0,72)$. 
Figura 2 - Porcentagem de soluções corretas e incorretas para o Estudo Dirigido “Qual

é o diagnóstico?” realizado cooperativamente $(n=51$ grupos) e colaborativamente $(n=55$ grupos) por estudantes de um Pré-vestibular Social, $\mathrm{X} 2=11,18, \mathrm{gl}$ 1, p = 0,0008.

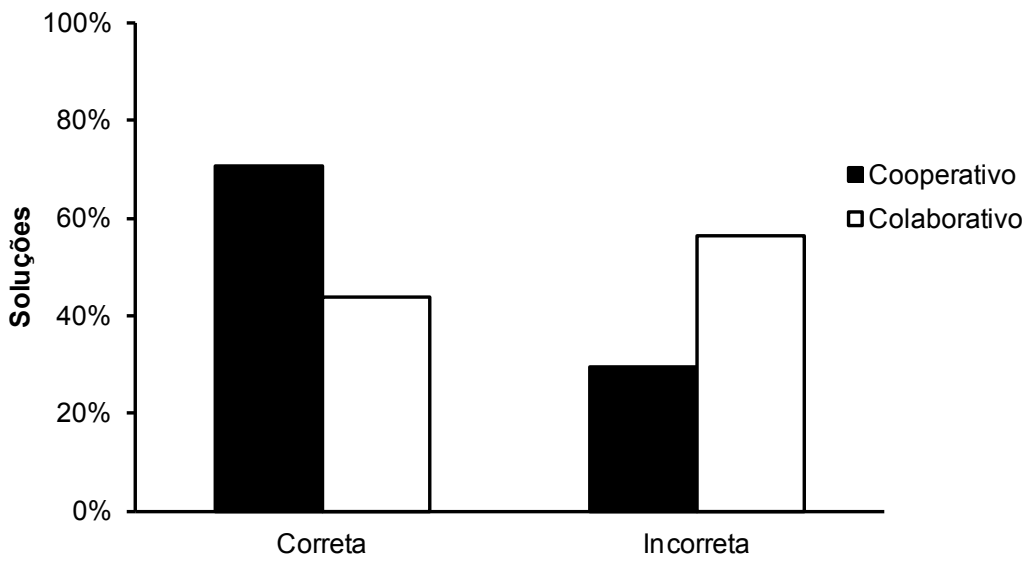

Fonte: dos autores.

O sucesso da estratégia cooperativa em relação à estratégia colaborativa pode ter sido devido à divisão de tarefas. Na estratégia cooperativa, cada componente do grupo ficou responsável por se aprofundar em um sintoma diferente e explicar o que aprendeu no grupo de experts aos demais membros do grupo de origem. Para se chegar ao diagnóstico, portanto, todos os membros do grupo devem participar da discussão, pois devido ao limite de tempo, não é possível que apenas um único membro analise todas as fichas e solucione o problema. Esta divisão de tarefas pode ter facilitado a organização das ideias e consequentemente ter favorecido a solução do problema. Na estratégia colaborativa não há divisão de tarefas a priori entre os membros, uma vez que não é formado o grupo de experts. De acordo com Brown e Palincsar (1989), na solução cooperativa de problemas, os membros do grupo dividem as responsabilidades, de maneira que cada participante é responsável por pensar e propor argumentos que serão parte da solução. Os argumentos propostos poderão ser usados para construir novos, atingindo assim um alto nível de complexidade que dificilmente seria alcançado por um único indivíduo.

Nos grupos colaborativos, diversos fatores podem reduzir o envolvimento dos indivíduos com o alcance dos objetivos. No presente caso, os alunos dos grupos colaborativos podem ter tido dificuldades em se organizar para analisar todas as fichas ou alguns alunos podem não ter contribuído para a discussão dentro do grupo. De acordo com Harkins e Perry (1982), por exemplo, os alunos podem reduzir suas contribuições para a realização do objetivo quando há esforços redundantes ou quando há falta de coesão do grupo. Segundo Latané et al. (1979) a redução de esforço individual que pode ocorrer quando pessoas trabalham em grupos, comparado quando as mesmas trabalham sozinhas é denominada "esforço mínimo" (ou social loafing, em inglês). No caso das estratégias cooperativas a divisão de tarefas dentro do grupo aumenta a responsabilidade individual e previne a ocorrência de ações de "esforço mínimo" pelos integrantes dos grupos. De acordo com Johnson e Johnson (2009) se a responsabilidade dos indivíduos dentro do grupo é alta, se os esforços redundantes são evitados, o grupo se torna coeso e se cada membro do grupo é responsável pelo resultado final coletivo, o “esforço mínimo” tende a desaparecer.

Há relatos na literatura de que a aprendizagem cooperativa tem resultados mais promissores na dinâmica do grupo do que a aprendizagem colaborativa. Gillies (2004), por exemplo, realizou um estudo com 234 adolescentes do ensino médio na Austrália. Os alunos foram divididos em dois grupos: cooperativo e não cooperativo. Os resultados mostraram que no grupo cooperativo os alunos escutavam mais o que o outro tinha a dizer, dividiam ideias e davam mais explicações quando solicitados ou não solicitados e do que no grupo colaborativo. Nos grupos colaborativos os alunos apresentaram mais interrupções negativas, como por exemplo, gritar para interromper os colegas e davam respostas mais curtas, sem muitos detalhes, aos demais membros do grupo. 
A análise da pergunta a respeito da percepção individual da dificuldade em solucionar o problema, revelou que não houve diferenças significativas entre as médias da dificuldade de solução do problema na estratégia cooperativa $(2,75 \pm 0,66)$ e estratégia colaborativa $(2,86 \pm 0,72)$. O valor próximo do meio da escala utilizada sugere que o problema não foi tão fácil a ponto de não desafiar os estudantes e nem tão difícil que fosse impossível de ser solucionado.

A análise do Questionário revelou também que as duas estratégias utilizadas na realização da Atividade foram bem aceitas pelos alunos, uma vez que a maioria dos alunos declarou que ela foi melhor ou muito melhor do que outras aulas de Biologia (Figura 3). Nenhum aluno considerou a Atividade pior ou muito pior do que as aulas. No entanto, os alunos que realizaram a Atividade colaborativamente tiveram uma preferência significativamente maior pela Atividade do que os alunos que a realizaram cooperativamente. Os resultados das respostas individuais dos alunos em relação à percepção de eventuais problemas ocorridos no grupo nos ajudam a explicar esta diferença. 24,4\% dos alunos que cooperaram perceberam problemas no grupo como desorganização e falta de participação de todos os membros, enquanto apenas $9 \%$ dos alunos que colaboraram perceberam estes problemas. Uma possível explicação é que na cooperação, os alunos formam dois grupos: o grupo dos experts e o grupo de origem. Fattareli et al. (2010), também descreveram dificuldades de organização em grupos de alunos de uma turma regular de Ensino Médio no desenvolvimento de estratégias Jigsaw bem sucedidas do ponto de vista do aprendizado. Embora as dificuldades tenham sido menos percebidas naquele estudo, nossa atividade foi avaliada em turmas formadas por alunos oriundos de uma grande variedade de escolas e de faixas etárias diversificadas (Bastos et al. 2010). É razoável supor, portanto, que nessas condições as dificuldades de organização para realização da estratégia cooperativa tenham sido mais percebidas. Outra possível explicação para a maior dificuldade de organização nos grupos cooperativos está relacionada à maior dependência dos grupos em relação ao trabalho de cada componente, ou seja, à responsabilidade individual dos estudantes (Jonhson et al. 1999). Esta responsabilidade individual é uma condição importante para que ocorra a aprendizagem cooperativa. No presente estudo cada indivíduo deveria analisar uma "ficha de consulta" e explicá-la aos colegas do grupo de origem, que não tinham acesso a esta informação. Caso este membro do grupo não realizasse adequadamente sua função, o grupo todo seria prejudicado, ao contrário dos grupos colaborativos, nos quais todos tinham acesso a todas as informações. Sendo assim, a falta de participação de um participante seria mais claramente percebida nos grupos cooperativos, refletindo-se nas dificuldades de organização. No entanto, estes problemas não comprometeram a solução correta da Atividade na estratégia cooperativa.

Figura 3 - Porcentagem de respostas para a afirmativa: "Comparando com outras aulas de Biologia, esta atividade foi:” dadas pelos alunos dos grupos cooperativos $(n=41)$ e colaborativos $(n=42), X^{2}=11,48, g l 2, p=0,0032$. Nenhum aluno assinalou as categorias Muito pior ou Pior.

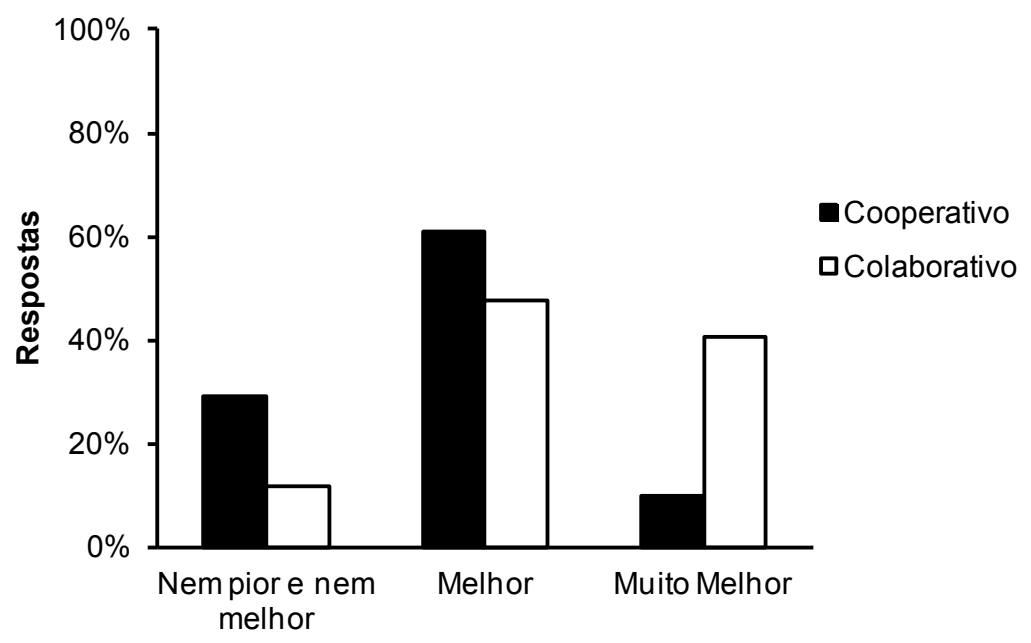

Fonte: dos autores. 
Alguns alunos declararam espontaneamente ao final da Atividade que se sentiram como verdadeiros médicos e para alguns isso afirmou ainda mais a vontade de seguir nesta carreira. Atividades que integram a aprendizagem cooperativa do tipo Jigsaw e o ensino por solução de problemas já foram relatadas com sucesso por outros autores. Apesar da aprendizagem dos estudantes de graduação que utilizaram a estratégia Jigsaw ter sido comparável à daqueles que aprenderam em aulas tradicionais, a maioria deles declarou ainda preferi-las às estratégias cooperativas (Persky \& Pollack, 2009). Esses resultados diferem amplamente dos nossos, nos quais a maioria dos estudantes que aprendeu cooperativamente ou colaborativamente preferiu tais estratégias às aulas tradicionais.

No Brasil, existem poucos estudos que relatam o desenvolvimento e avaliação de estratégias cooperativas de ensino de Biociências. A maioria deles é voltada para o ensino de Química (Silva, 2007; Queiroz et al. 2009; Fatareli et al. 2010; Teodoro, 2011) ou para a área de Educação Física (Broto, 2001). Apenas o trabalho de Leite et al. (2013) e Martins et al. (2012) abordam o tema Biociências. Queiroz et al. (2009) combinaram os métodos cooperativos Jigsaw e um outro método denominado de jogos de torneios em grupos (Teams Games-Tournament) no ensino de química orgânica para alunos do $3^{\circ}$ ano do Ensino Médio em Pernambuco. Os alunos participaram ativamente das discussões, elaborando, reestruturando e sistematizando o conteúdo, assim como fornecendo explicações. Leite et al. (2013) realizaram um minicurso de nanociência e nanotecnologia para 80 alunos do Ensino Médio utilizando o método cooperativo Jigsaw. Os resultados mostraram que a utilização da técnica permitiu que os alunos ampliassem e correlacionassem os conceitos sobre o assunto. Martins et al. (2012) desenvolveram um jogo cooperativo que aborda o tema "Mata Ciliar" com o objetivo de explorar aspectos ambientais, sociais e econômicos nos processos de intervenção e recuperação dessa formação arbórea. O jogo foi utilizado com 24 alunos do Ensino Fundamental de uma escola estadual em São Paulo. Os autores constataram que o jogo despertou o interesse e a curiosidade para o tema. Além disso, fomentou debates entre os alunos e a adoção de atitudes cooperativas durante a partida. Os resultados mostraram que a estratégia teve boa receptividade e os alunos tiveram a percepção de que a mesma contribuiu para o aprendizado. No entanto, nenhum deles compara a aprendizagem de temas de biociências por meio de estratégias cooperativas e colaborativas. Nosso trabalho contribui para preencher esta lacuna. Nossos resultados, somados às conclusões obtidas de pesquisas semelhantes já realizadas, tanto no Brasil quanto no exterior, parecem legitimar a conclusão de que há uma tendência geral de aprendizagem eficiente e atitudes positivas em associação com o uso de estratégias de aprendizagem cooperativa para este nível de ensino.

\section{CONSIDERAÇÕES FINAIS}

No presente trabalho descrevemos uma Atividade intitulada “Qual é o diagnóstico?” que integra diferentes sistemas fisiológicos através da solução de um problema, tendo em vista que na maioria das vezes os sistemas são estudados de maneira separada. Além disso, utilizamos estratégias cooperativas e colaborativas para investigar se a estruturação do grupo tem impacto na solução do problema e na aceitação da Atividade. Os resultados mostraram que os alunos que realizaram a atividade cooperativamente tiveram uma porcentagem de acertos significativamente maior na solução do problema do que os alunos que colaboraram durante a mesma tarefa. É possível que na estratégia colaborativa nem todos os membros do grupo tenham se envolvido na solução do problema, comprometendo assim o desempenho coletivo. Essa diminuição do desempenho individual dentro de um grupo é conhecida na literatura como “esforço mínimo" (Latané e cols, 1979; Willians e cols, 1981), o que explicaria um desempenho menor dos grupos colaborativos quando comparados aos cooperativos. O presente estudo confirma a ideia de que colocar os alunos para trabalhar em grupo não assegura que todos irão participar (Blumenfeld, 1996). De acordo com Johnson e Johnson (2009), quando a responsabilidade dos indivíduos dentro do grupo é alta, são evitados esforços redundantes, o grupo torna-se coeso e o "esforço mínimo" desaparece. A divisão de tarefas dentro do grupo cooperativo, portanto, pode ter evitado o "esforço mínimo". 
A alta proporção de soluções corretas utilizando a estratégia cooperativa sugere que a solução do problema proposto não se mostrou tão próxima do estado de desenvolvimento dos estudantes que representasse uma estagnação, nem tão distante que representasse um desafio inultrapassável, combinação que, segundo Cochito (2004, p.21) constitui uma oportunidade adequada para o desenvolvimento da cooperação. Situações deste tipo são propícias à aprendizagem cooperativa, uma vez que o trabalho com um colega se situa mais facilmente na zona de desenvolvimento proximal dos estudantes. Neste contexto, a divisão de tarefas, ao tornar essencial a contribuição de todos os participantes, ofereceu a todos eles a oportunidade de poder ensinar os colegas, o que favorece a assimilação e a reorganização do aprendido de forma mais efetiva (Cochito, 2004).

Bruffee (1992) argumenta que a aprendizagem cooperativa visa contribuir para o aprendizado de conhecimentos fundamentais por estudantes da educação básica. No aprendizado cooperativo há necessidade de definição clara das regras de trabalho coletivo, com a atribuição, pelo professor, de funções definidas para cada aluno. Na estratégia Jigsaw aqui avaliada, cada estudante retorna ao grupo de origem como único conhecedor de um conjunto de informações relevantes para a solução do problema, tornando-os individualmente responsáveis pelo aprendizado coletivo. A colaboração, por outro lado seria destinada à discussão de temas e problemas sem soluções definidas ou consensuais, por alunos mais experientes (Bruffee, 1992).

Os alunos dos grupos cooperativos identificaram mais problemas na dinâmica de grupo do que aqueles dos grupos colaborativos. Além disso, os alunos de grupos colaborativos tiveram uma preferência maior pela atividade em relação aos que cooperaram. $\mathrm{O}$ fato de terem formado dois grupos diferentes (origem e especialistas) pode ter comprometido a dinâmica da estratégia cooperativa, o que é compreensível considerando-se a grande heterogeneidade das turmas participantes de nosso estudo. Porém, ambas as estratégias tiveram larga preferência dos alunos em relação a aulas tradicionais. $\mathrm{O}$ fato de a atividade proposta apresentar um problema cuja solução depende da compreensão integrada da fisiologia humana é relevante, uma vez que pode indicar caminhos para lidar com a compartimentalização de conteúdos desse tema, comum no ensino de ciências. Assim, o melhor desempenho dos grupos cooperativos na solução de um problema de fisiologia com solução definida, somado ao fato desta abordagem ter sido bem recebida pelos alunos, corrobora a maior adequação de estratégias cooperativas em relação às colaborativas no caso do Ensino Médio.

Finalmente, a cooperação tem o benefício de contribuir para a integração social dos estudantes, por meio da eliminação da competição e da realização de trabalho coletivo organizado (Bruffee, 1992). O sucesso da estratégia cooperativa no contexto de um pré-vestibular social sugere que abordagens semelhantes poderiam ser importantes ferramentas para o ensino de temas específicos de Ciências e Biologia em contextos de ensino com estudantes de origens diversas, tais como as séries iniciais de escolas públicas de ensino médio ou universidades com dois ou mais sistemas de acesso concomitantes. 


\section{REFERÊNCIAS}

ARONSON, E., \& PATNOE, S. The jigsaw classroom: Building cooperation in the classroom. New York: Longman. 1997.

ASPY, D. N.; ASPY, C. B.; QUIMBY, P. M. What doctors can teach teachers about problem-based learning? Educational Leadership, v. 50, n. 7, p. 22-24, 1993.

BASTOS, M. D. F., GOMES, M. F. C. M., \& FERNANDES, L. L. O Pré-Vestibular social: desafios à busca da inclusão social. Revista EAD em Foco, v. 1, n. 1, p. 123-158, 2010.

BLUMENFELD, P. C., MARX, R. W., SOLOWAY, E., \& KRAJCIK, J. Learning with peers: From small group cooperation to collaborative communities. Educational Researcher, v. 25, n. 8, p. 37-40, 1996.

BRASIL. Parâmetros Curriculares Nacionais: Ensino Médio. Ministério da Educação. Secretaria de Educação Média e Tecnológica. Brasília-DF, 2000.

Profissionalização de Auxiliares de Enfermagem. Cadernos do Aluno. Ministério da Saúde. BrasíliaDF, 2003.

Hipertensão arterial sistêmica. Cadernos de Atenção Básica n. ${ }^{0} 15$ - Série A. Normas e Manuais Técnicos. Brasília-DF, 2006.

Diabete Mellitus Cadernos de Atenção Básica no 16 - Série A. Normas e Manuais Técnicos. BrasíliaDF, 2006.

BROTO, F. O. Jogos cooperativos: se o importante é competir, o fundamental é cooperar! Ed.Re-Novada. Santos,SP: Projeto Cooperação, 1997.

BROWN, A. L.; PALINCSAR, A. S. Guided, cooperative learning and individual knowledge acquisition. Knowing, learning, and instruction: Essays in honor of Robert Glaser, p. 393-451, 1989.

BRUFFEE, K. A. Sharing our toys: Cooperative learning versus collaborative learning. Change: The Magazine of Higher Learning, v. 27, n. 1, p. 12-18, 1995.

COCHITO, M.I.S. Cooperação e aprendizagem: educação intercultural. Lisboa: ACIME, 2004. Disponível em: <https://infoeuropa.eurocid.pt/files/database/000040001-000041000/000040616.pdf >. Acessado em: $11 \mathrm{de}$ nov. 2014.

DEES, R. L. The role of cooperative learning in increasing problem-solving ability in a college remedial course. Journal of Research in Mathematics Education, v. 22, n. 5, p. 409-421, 1991.

DILLENBOURG P. What do you mean by collaborative learning? In P. Dillenbourg (Ed.), Collaborativelearning: cognitive and computational approaches. Elsevier, Oxford, p. 1-19, 1999.

DUCH, B. J., GROH, S. E., \& ALLEN, D. E. Why problem-based learning? A case study of institutional change in undergraduate education. In: B. Duch, S. Groh, \& D. Allen (Eds.) The power of problem-based learning. Virginia, Stylus publishing, 2001.

EBRAHIM, A. The effect of cooperative learning strategies on elementary students'science achievement and social skills in Kuwait. International Journal of Science and Mathematics Education, v. 10, n. 2, p. 293-314, 2012.

FAILACE, R. Hemograma: Manual de Interpretação. Porto Alegre: Artmed, 2009. 
FATARELI, E. F., FERREIRA, L. N. A., FERREIRA, J. Q., \& QUEIROZ, S. L. Método cooperativo de aprendizagem Jigsaw no ensino de cinética química. Química Nova na Escola, v. 32, n. 3, p. 161-168, 2010.

GAUDET, A. D., RAMER, L. M., NAKONECHNY J., CRAGG, J. J., RAMER, M. S. Small-Group learning in an upper-Level university Biology class enhances academic performance and student attitudes toward group work. Plos One, v. 5, n. 12, 2010

GILLIES, R. M. The effects of cooperative learning on junior high school students during small group learning. Learning and Instruction. v. 14, n. 2, p. 197-213, 2004.

HARKINS, S. G. \& PERRY, R. E. Effects of task difficulty and task uniqueness on social loafing. Journal of Personality and Social Psychology. v. 43, n. 6, p. 1214-1229, 1982.

HELLER, P. \& HOLLABAUGH, M. Teaching problem solving through cooperative grouping. Part 1: Group versus individual problem solving. American Journal of Physics. v. 60, n. 7, p. 627-636, 1992.

HMELO-SILVER, C. E. “Problem-Based Learning: What and How Do Students Learn?” Educational Psychology Review. v. 16, n. 3, p. 235-266, 2004.

JOHNSON, D. W. \& JOHNSON, R. T. An educational psychology success story: social interdependence theory and cooperative learning. Educational Research. v. 38, n. 5, p. 365-379, 2009.

JOHNSON, R. T., JOHNSON, D. W., \& STANNE, M. B. Cooperative learning methods: a meta-analysis, 2000. Retrieved from <http://www.ccsstl.com/sites/default/files/Cooperative\%20Learning\%20Research\%20. pdf $>$. Acessado em: 25 nov. 2013.

KEMCZINSKI, A., MAREK, J., HOUNSELL, M. S., GASPARINI, I. Colaboração e cooperação - pertinência, concorrência ou complementaridade. Revista Produção Online. v. 7, n. 3, p. 1-15, 2007.

KIRSCHNER, F., PAAS, F., KIRSCHNER, P. A. A cognitive load approach to collaborative learning: United brains for complex tasks. Educational Psychology Review, v. 21, n. 1, p. 31-42, 2009.

LATANÉ, B.; WILLIANS, K. \& HARKINS, S. Many hands make light the work: the causes and consequences of social loafing. Journal of Personality and Social Psychology. v. 37 n. 6, p. 822-832, 1979.

LEITE, I. S., LOURENÇO, A. B., LICIO, J. G., \& HERNANDES, A. C . Uso do método cooperativo de aprendizagem Jigsaw adaptado ao ensino de nanociência e nanotecnologia. Revista Brasileira de Ensino de Fisica. v. 35 n. 4, p. 4504-4507, 2013.

MARTINS, L. C.; CONTIER, D.; NAVAS, A. M.; MINGUES, E., \& MONACO, L. M. O processo de avaliação na educação não formal: análise do caso do jogo cooperativo Ciliares. Revista do Encontro de Divulgação de Ciência e Cultura. v. 1, n. 1, p. 305-313, 2012.

MCINNERNEY, J. M. \& ROBERTS, T. S. (2004). Collaborative or cooperative learning?. In: T. S. Roberts (ed). Online collaborative learning: theory and practice. Hershey, PA: information science publishing, p. 203-214, 2004.

NORMAN, G. R. \& SCHMIDT, H. G. Effectiveness of problem-based learning curricula: theory, practice and paper darts. Medical Education. v. 34, n. 9, p. 721-728, 2000.

PAIVA, A. A.; RONDÓ, P. H. C; GUERRA-SHINOHARA, E. M. Parâmetros para avaliação do estado nutricional de ferro. Revista de Saúde Pública. v. 34, n. 4, p. 421-426, 2000. 
PANITZ, T. Collaborative versus cooperative learning: a comparison of the two concepts which will help us understand the underlying nature of interactive learning. Disponível em: http://home.capecod.net/ tpanitz/ tedsarticles/coopdefinition.htm Acessado em 10/03/2013. 1997.

PELAEZ, N. J. Problem-based writing with peer review improves academic performance in physiology. Advances in Physiology Education. v. 26, n. 3, p. 174-184, 2002.

PERSKY, A. M. \& POLLACK, G. M. A hybrid jigsaw approach to teaching renal clearance concepts. American Journal of Pharmaceutical Education. v. 73, n. 3, p. 1-6, 2009.

RODRÍGUEZ-BARBERO, A. \& LOPEZ-NOVOA, J. M. Teaching integrative physiology using the quantitative circulatory physiology model and case discussion method: evaluation of the learning experience. Advances in Physiology Education, v. 32, n. 4, p. 304-311, 2008.

QUEIROZ, M. P.; BARBOSA, R. M. N. \& AMARAL, E. M. R. Uma análise de interações discursivas promovidas pela aplicação de métodos cooperativos em aulas de química. Revista Brasileira de Pesquisa em Educação em Ciências.v. 9, n. 3, 2009, pp: 1-20.

SHARAN, Y. Cooperative learning for academic and social gains: valued pedagogy, problematic practice. European Journal of Education, v. 45, n. 2, p. 300-313, 2010.

SILVA, A. J. \& GAUCHE, R. Aprendizagem cooperativa no ensino de química: uma proposta de abordagem em sala de aula. Anais do VII Encontro Nacional de Pesquisa e Educação em Ciências. 2009. Disponível em: <http://posgrad.fae.ufmg.br/posgrad/viienpec/pdfs/1271.pdf > . Acessado em: 12/03/2013.

SLAVIN, R. E. When does cooperative learning increase student achievement?. Psychological bulletin, v. 94, n. 3, p. 429-445, 1983.

SLAVIN, R. E. Cooperative learning: what makes group work work. In: Hanna, D., David, I., \& Francisco, B. (Eds.). The Nature of Learning Using Research to Inspire Practice: Using Research to Inspire Practice. OECD Publishing. 2010.

TARIM, K. The effects of cooperative learning on preschoolers' mathematics problem-solving ability. Educational Studies in Mathematic, v. 72, p. 325-340, 2009.

TEODORO, D. L. Aprendizagem cooperativa no ensino de química: investigando uma atividade didática elaborada no formato jigsaw. (2011). Tese de doutorado Universidade de São Paulo, São Paulo- SP.

TORRES, P. L.; IRALA, E. A. F. Aprendizagem colaborativa. In: Algumas vias para entretecer o pensar e o agir. 1. ed. SENAR-PR: Curitiba, p. 65-97, 2007.

VANZELA, E. C., BALBO, S. L., \& JUSTINA, L. A. D. A integração dos sistemas fisiológicos e sua compreensão por alunos do nível médio. Arquivos do Museu Dinâmico Interdisciplinar. v.11, n.3, p. 12-19, 2013. 


\subsubsection{Apêndice I: Atividade Qual é o diagnóstico?}

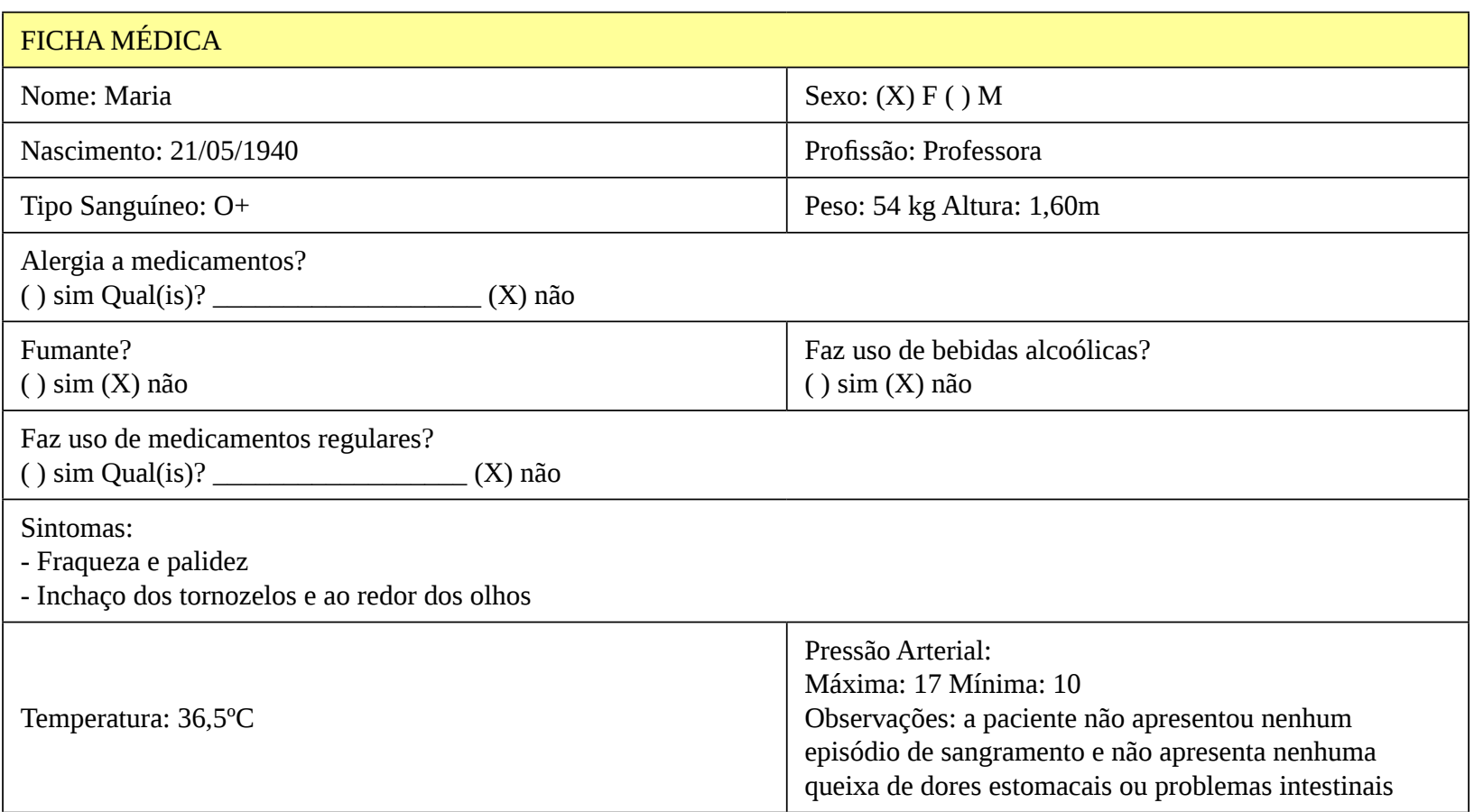

Analise cada um dos sintomas e identifique qual o problema de saúde do paciente explicando os motivos que levaram vocês a chegarem a esta conclusão.

\section{1 Pressão arterial}

Os valores que permitem classificar a pressão arterial dos indivíduos adultos acima de 18 anos estão na tabela abaixo.

\begin{tabular}{|c|c|c|}
\hline \multicolumn{3}{|c|}{ Classificação da Pressão Arterial em indivíduos maiores de 18 anos } \\
\hline Classificação & Pressão máxima & Pressão mínima \\
\hline Normal & $<120$ & $<80$ \\
\hline Pré-hipertensão & $120-139$ & $80-89$ \\
\hline $\begin{array}{c}\text { Hipertensão arterial } \\
\text { Estágio 1 }\end{array}$ & $140-159$ & $90-99$ \\
\hline $\begin{array}{c}\text { Hipertensão arterial } \\
\text { Estágio 2 }\end{array}$ & $\geq 160$ & $\geq 100$ \\
\hline
\end{tabular}

Fonte: Brasil. Ministério da Saúde, 2006.

\section{2 Hipertensão arterial (em geral conhecida como "pressão alta”)}

É um estado alterado da saúde no qual a pressão do sangue está acima das medidas consideradas normais por um período longo de tempo. 


\section{3 Causas da hipertensão arterial}

As causas hipertensão arterial podem ser divididas em: primária, responsável pela maioria dos casos (cerca de 95\%), e secundárias, de causas variadas e em geral curáveis. A hipertensão primária tem grande componente hereditário e geralmente se manifesta a partir dos 30-40 anos de idade. Seu tratamento é feito ao longo da vida com medicações anti-hipertensivas.

As causas da hipertensão secundária são variadas, mas todas têm em comum o fato de serem potencialmente curáveis. Entre os motivos mais freqüentes, destacam-se:

a. Insuficiência Renal: $\mathrm{O}$ aumento da pressão arterial na insuficiência renal está relacionado à perda progressiva da capacidade dos rins em excretar sódio, resultando em uma sobrecarga salina e de volume de sangue nos vasos.

b. Obesidade: Indivíduos obesos com frequência consomem alimentos altamente calóricos e industrializados. Estes alimentos contêm elevados níveis de sal (sódio). Por isso a obesidade pode levar a um aumento na pressão arterial, pois como o sangue está com uma elevada concentração de sódio, o líquido presente nos tecidos retorna para dentro dos vasos sanguíneos, aumentando a pressão sobre suas paredes. Os obesos possuem também maiores volumes de sangue. Esse aumento do volume de sangue circulante (hipervolemia) também aumenta a pressão sobre as paredes dos vasos sanguíneos.

c. Diabetes Tipo II: Na diabetes tipo II o organismo aumenta a produção de insulina. O aumento da insulina provoca um aumento na retenção do sódio e estimula o sistema nervoso simpático. Os nervos simpáticos levam a um aumento dos batimentos cardíacos e contraem os vasos sanguíneos o que leva a um aumento na pressão.

Após analisar a ficha médica e os motivos que levam ao aumento da pressão podemos concluir que o paciente PODE estar com (marque mais de uma opção se julgar necessário):

( ) Insuficiência Renal ( ) Obesidade ( ) Diabetes tipo II

\section{4 Exame}

Este exame vocês deverão analisar para discutirem com seu grupo

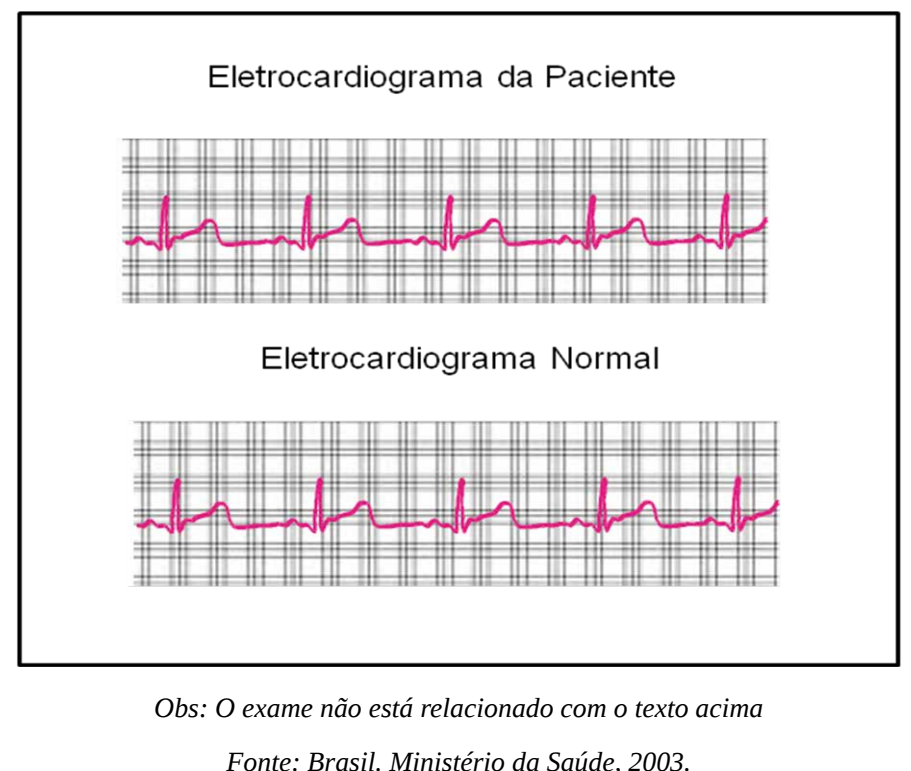


Análise:

O exame está: ( ) Normal ( ) Alterado. Por quê?

\section{5 Fraqueza e palidez anormal}

Fraqueza e palidez anormal podem ser sintomas de anemia. Anemia é o nome que se dá quando ocorre uma diminuição da quantidade de glóbulos vermelhos do sangue (hemácias). Como as hemácias transportam o oxigênio, a falta delas leva a uma oxigenação deficiente das células. A anemia pode ser confirmada através de um exame de sangue.

\section{6 Resultado do hemograma}

\begin{tabular}{|c|c|c|}
\hline \multicolumn{3}{|c|}{ Exame de sangue- Série Vermelha } \\
\hline & Obtido & $\begin{array}{c}\text { Valores de Referência } \\
\text { (mulheres) }\end{array}$ \\
\hline Hemácias & $\begin{array}{c}4,9 \\
\text { milhões } / \mathrm{mm}^{3}\end{array}$ & $\begin{array}{c}4 \text { a } 5,4 \\
\text { milhões } / \mathrm{mm}^{3}\end{array}$ \\
\hline Hemoglobina & $15 \mathrm{~g} / \mathrm{dL}$ & 12 a $16 \mathrm{~g} / \mathrm{dL}$ \\
\hline Hematócrito & $42 \%$ & 36 a $48 \%$ \\
\hline
\end{tabular}

* HEMATÓCRITO é a porcentagem do volume das hemácias em relação ao volume sanguíneo total. Fonte: Failace, 2009.

A anemia pode ser causada por:

a. Hemorragia - perda de hemácias através de sangramentos:

Uma úlcera no estômago ou um câncer de intestino causam sangramentos e perda de hemácias, levando à anemia.

\section{b. Insuficiência renal}

O rim diminui sua capacidade de produzir um hormônio (eritropoetina) que controla a produção de hemácias (glóbulos vermelhos) pela medula óssea. Com isso o paciente apresenta queda no seu hematócrito e anemia.

\section{c. Deficiência de Ferro}

O ferro é um dos principais constituintes da hemoglobina. A anemia por carência de ferro (ou anemia ferropriva) ocorre quando as reservas de ferro do organismo não são suficientes para a produção de hemoglobina e, conseqüentemente, não permitem a produção das hemácias.

Após analisar a ficha médica e os motivos que levam o indivíduo apresentar fraqueza e palidez podemos concluir que o paciente PODE estar com (marque mais de uma opção se julgar necessário):

( ) Hemorragia ( ) Insuficiência Renal ( ) Deficiência de Ferro 


\section{7 Exame}

Este exame vocês deverão analisar para discutirem com seu grupo

Obs: O exame não está relacionado com o texto acima

\section{GLICOSE}

Valores normais de referência: $<110 \mathrm{mg} / \mathrm{dL}$

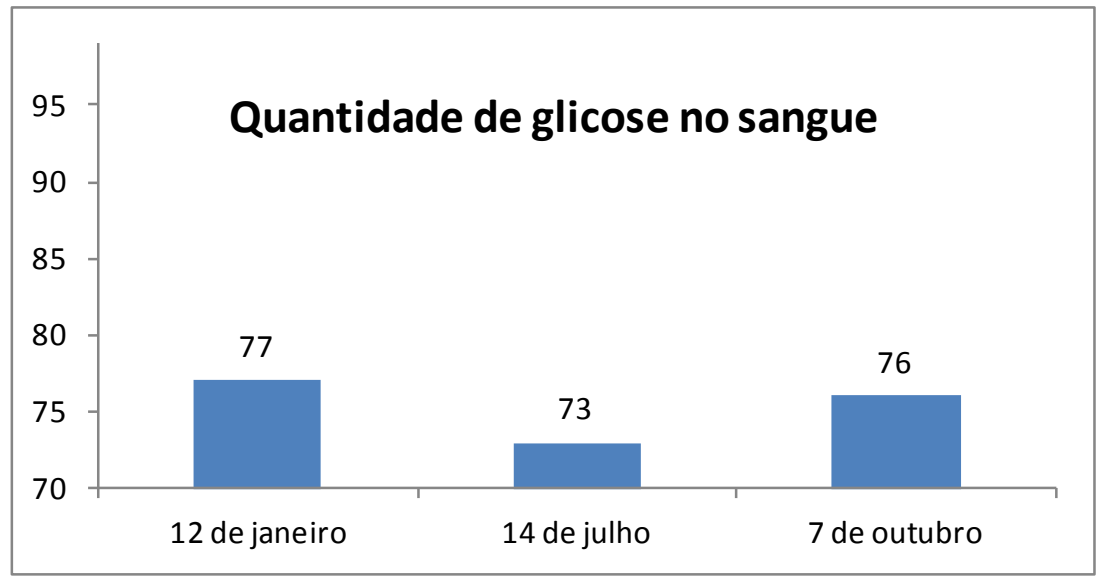

Fonte: Brasil. Ministério da Saúde, 2006

Os níveis de glicose estão:

( ) Normais

( ) Alterados. Por quê?

\section{8 Inchaço dos tornozelos}

Edema é o nome que se dá a um inchaço localizado. Os edemas mais conhecidos são os que ocorrem nas pernas. No entanto eles podem ocorrer em diversas partes do corpo como: pulmões, cérebro e língua. Ao contrário do que se imagina, os vasos sanguíneos não são totalmente impermeáveis. Eles permitem a saída e entrada de líquido. O inchaço ocorre quando há um aumento da permeabilidade dos vasos e com isso excesso de saída de líquido para o espaço existente entre as células de um tecido ou órgão. Existem outros mecanismos para formação do edema além do aumento da permeabilidade dos vasos:

\section{a. Aumento da pressão dentro das veias e capilares}

Esse aumento nada tem a ver com hipertensão, que é a elevação da pressão arterial. Um conhecido exemplo são as varizes nas pernas. Varizes são veias defeituosas que apresentam dificuldade em levar o sangue de volta ao coração.

\section{b. Insuficiência cardíaca}

O coração deficiente não consegue bombear o sangue de modo eficaz, favorecendo seu represamento nas pernas. Nestes casos o edema surge e piora quando o paciente fica muito tempo em pé e tende a desaparecer após algumas horas deitado. 


\section{c. Insuficiência Renal}

Na insuficiência renal, ocorre um acúmulo de sal no corpo devido à perda da capacidade renal de excretar sódio. Esse excesso de sal aumenta a quantidade de água corporal, que, em consequência, aumenta a pressão, favorecendo o aparecimento de inchaços. Após analisar a ficha médica e os motivos que levam o indivíduo apresentar inchaço dos tornozelos podemos concluir que o paciente PODE estar com (marque mais de uma opção se julgar necessário):

( ) Varizes ( ) Insuficiência Cardíaca ( ) Insuficiência Renal

\section{9 Exame}

Este exame vocês deverão analisar para discutirem com seu grupo de origem

Obs: O exame não está relacionado com o texto acima

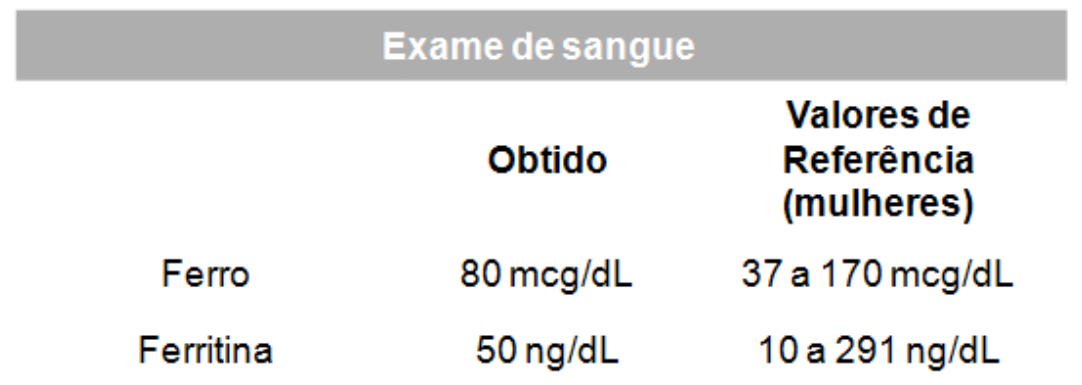

Fonte: Paiva, Rondo e Guerra-Shinohara, 2000.

*Ferritina: proteína que armazena ferro

O exame está:

( ) Normal ( ) Alterado 